\title{
Recent innovations in hazard and risk analysis
}

\author{
Giulio Iovine $^{1} \cdot$ Christoph Aubrecht $^{2} \cdot$ Denis $_{\text {Cohen }}^{3} \cdot$ Manuel Pastor $^{4}$
}

Received: 13 February 2018/Accepted: 11 March 2018/Published online: 28 March 2018

(C) Springer Science+Business Media B.V., part of Springer Nature 2018

Risk to people and properties commonly derives from different types of dangerous phenomena, either natural or man-made. The potential worth of loss depends on vulnerability of the exposed elements at risk, and on worth of these latter. Vulnerability generally refers to heterogeneous sets of elements and should be analysed by considering both actual and expected conditions, in terms of exposure and of potential effects on economic activities, environmental education and availability of authorities for forecasting and monitoring. Furthermore, the probability of occurrence (hazard) of a given type of phenomenon must be evaluated within a specific zone and temporal frame of interest. The above factors are all needed to assess the overall risk, but they can be very difficult to measure.

If different types of dangerous phenomena threaten a given site, or when cascading effects are expected, the evaluation of the combined risk is required, with overlapping and

\section{Giulio Iovine}

giulio.iovine@cnr.it

Christoph Aubrecht

caubrecht@worldbank.org; christoph.aubrecht@esa.int

Denis Cohen

denis.cohen@gmail.com

Manuel Pastor

manuel.pastor@upm.es

1 CNR-IRPI (Italian National Research Council - Research Institute for Geo-Hydrological Protection), Cosenza, Italy

2 European Space Agency (ESA) and World Bank, 1818 H St NW, Washington, DC 20433, USA

3 Department of Earth and Environmental Science, New Mexico Tech, 801 Leroy Place, Socorro, NM 87801, USA

4 Universidad Politécnica de Madrid - ETS Caminos, Prof. Aranguren Street s/n, 28040 Madrid, Spain 
amplification issues often hard to quantify. To decrease the level of risk at local or regional scales, different techniques are available, based on inventories, spatial analyses, damage mapping, vulnerability and susceptibility mapping, numerical modelling, monitoring, and land-use planning, in addition to knowledge dissemination and realising of remedial works. Real-time monitoring systems may allow to implement early warning procedures for civil protection and, if combined with innovative modelling techniques, may help in defining reliable standards and implementing effective strategies for risk mitigation.

The nine papers collected in this special issue essentially derive from studies on the above mentioned topics, discussed at:

- Session EGU2016 NH9.9 on "Monitoring and modelling of dangerous phenomena, and innovative techniques for hazard evaluation and risk mitigation" Conveners: Giulio Iovine, Johannes Huebl, Christoph Aubrecht, Manuel Pastor http://meetingorganizer. copernicus.org/EGU2016/session/20334.

- Session EGU2015 NH3.6 on "Advanced methods in landslides research: modelling" Conveners: Giulio Iovine, Denis Cohen http://meetingorganizer.copernicus.org/ EGU2015/session/18763.

- Session EGU2015 NH9.12 on "Modelling of dangerous phenomena, and innovative techniques for hazard evaluation and risk mitigation" Conveners: Giulio Iovine, Johannes Huebl, Christoph Aubrecht, Manuel Pastor http://meetingorganizer. copernicus.org/EGU2015/session/18752.

The topics dealt in the papers are quite differentiated, ranging from flood-related issues (cf. Hsu et al. 2017; Tzavella et al. 2017; Persi et al. 2017), to slope stability (cf. Goorchi et al. 2017; Canli et al. 2017; Yin and Zhang 2018), to earthquakes (Mignan et al. 2016), sinkholes (Guarino et al. 2017), and radon anomalies (Iovine et al. 2017). This special issue therefore covers a broad range of topics, addressing wide scope and integrative nature of disaster risk management.

More in detail, regarding the first group of papers, in "A hurricane surge risk assessment framework using the joint probability method and surge response functions", Hsu and co-workers start from observing that, all over the world, Hurricane surge events have caused devastating damage. Authors have therefore focused their study to develop a framework for evaluating hurricane flood risk and identifying prone areas, aiming at predicting surge elevations and then saving human lives. The adopted approach is based on the joint probability method with optimal sampling using surge response functions. After assuming several simplifications, the framework is applied to three study areas in the Gulf of Mexico, exhibiting similar surge hazard exposures.

In "Opportunities provided by geographic information systems and volunteered geographic information for a timely emergency response during flood events in Cologne, Germany", Tzavella and colleagues focus on the impact induced by extreme flooding in urban environments on critical infrastructures, which are of vital importance for emergency response. A model is described that could be used from emergency responders for timely and efficient emergency management in urban complex environments. By considering an extreme flood scenario for the city of Cologne, authors indicate possible ways to decrease the emergency response through the development of an accessibility indicator. In addition, the opportunities of using combined Volunteered Geographic Information and open-source data to increase urban resilience and decrease emergency response time are investigated. As a result, geo-located information provided by refugees may result useful in emergency situations. 
Persi and co-authors deal with a "Large wood transport modelling by a coupled Eulerian-Lagrangian approach". In their study, a model able to predict the trajectory of floating rigid bodies such as woody "debris" during floods is presented. The model couples a Discrete Element Lagrangian approach for the calculation of motion of rigid bodies with the Eulerian solution of the shallow water equations to simulate the transport of a cylinder in a two-dimensional stream. A dynamic approach is adopted, by adapting the Basset-Boussinesq-Oseen equation. A set of laboratory tests on partially submerged cylinders allowed to validate the simulated transport of spheres and wooden cylinders.

As for the second set group, in "A new rating system approach for risk analysis of rock slopes", Goorchi and colleagues describe an approach to analyse the stability of rock slopes based on a new rating system. Failure probability, element at risk rating, and vulnerability rating are the factors considered the estimate the risk level. An example of application of the method to the western sector of the slopes facing Songun copper plant is discussed for testing purposes.

In the paper titled "Spatially distributed rainfall information and its potential for regional landslide early warning systems", Canli and co-workers stress that the precise prediction of rainfall in space and time is crucial to landslide early warning systems. To such purpose, authors suggests an automated approach from a hourly, Web-based collection of rain gauge data to the generation of spatially differentiated rainfall predictions via deterministic and geostatistical methods. Validation shows satisfactory results and reveals drawbacks associated with univariate geostatistical interpolation techniques (only relying on rain gauges).

Yin and Zhang deal with "Hazard regionalization of debris-flow disasters along highways in China". Authors notice significant differences in the distributions of debris-flow disasters along highways, with related difficulties in forecasting, identification, and early warning implementation. Even analysing single-gully debris-flow disasters, the inherent mechanisms leading to their occurrence along the highways are not properly clarified. Thanks to a regionalization scheme, authors identified hazard sources of such phenomena, extracted hazard indicators, and calculated weights of each indicator by means of a cloud model-improved analytic hierarchy process. The obtained degrees of hazard in China look very different from site to site, with highest values characterising the Loess Plateau-north part of Mt. QinBa, the Taiwan-Mt. Wuyi, the Sichuan-Mt. Yunnan, and the TianshanMt. Kunlun.

In their study on "Considering large earthquake clustering in seismic risk analysis", Mignan and co-authors underline that earthquakes cluster, in space and time, producing nonlinear damage effects. Authors analyse earthquake interactions by the Coulomb stresstransfer theory and dynamic vulnerability from the concept of ductility capacity reduction. Processes are combined into a generic multi-risk framework, where risk scenarios are simulated based on a variant of the Markov chain-Monte Carlo method. The approach is tested on a thrust fault system in northern Italy, by considering earthquakes with magnitudes of 6-6.5, different levels of tectonic loading, and a generic stock of fictitious low-rise buildings with different ductility capacities. Process' stochasticity is described by nonstationary Poisson earthquake probabilities and binomial damage state probabilities. Among the results, the impact of clustering reveals more important than dynamic vulnerability, the spatial extent of the former phenomenon being greater.

Guarino and co-workers, in their "Analysis of a database for anthropogenic sinkhole triggering and zonation in the Naples hinterland (Southern Italy)", notice that-especially in urban contexts-anthropogenic sinkholes are generally due to the collapse of man-made underground caves and pose a major threat to people, buildings, and lifelines. In particular, 
the hinterland of Naples was historically affected by numerous sinkholes. Based on data collected into a data base of man-made caves and sinkholes, the causal factors were analysed aiming at sinkhole susceptibility zonation. Presence of pre-existing of caves within the volcanic bedrock (Campanian Ignimbrite tuff) and the geometric features of their network result to be mostly relevant predisposing factor for sinkhole development. As a rule, the shallower the depth of the chamber roof and the lower the thickness of the vault, the higher is the observed frequency of sinkholes. The main triggering mechanism consists in saturation of the subsoil, due to water leaks coming from buried sewage and water pipelines.

In "Soil-gas radon anomalies in three study areas of Central-Northern Calabria (Southern Italy)", Iovine and co-authors deal with the influence of fault zones on anomalous radon concentrations in soil by integrated geophysical and geostructural analyses in three study areas of central-northern Calabria. Based on soil-gas radon surveys carried out at 12,509 locations between 2002 and 2004, the spatial distribution of concentrations is analysed by a geostatistical approach. In the considered areas, no appreciable differences can be noticed among lithotypes, with the highest concentration values measured in alluvial deposit and in clay. Furthermore, measurements reveal anomalies clearly connected to the tectonic structures, whose recent activity is confirmed by the distribution of epicentres of historical earthquakes occurred between 1184 and 2001. Concentrations generally increase, as expected, with decreasing distance to the faults. In the paper, a schematic review of worldwide data on soil-gas radon amounts versus geological features (outcropping lithotypes, presence and type of geological structures) is also presented.

The above set of papers offers an interesting view on some recent approaches to hazard evaluation and mapping, and to risk analysis and management. Pros and cons of the adopted approaches can be inferred from the presented case studies and related discussions. Nevertheless, further efforts are still needed to improve objectiveness and reliability of the available approaches for attempting successful applications in risk management and landuse planning.

\section{References}

Canli E, Loigge B, Glade T (2017) Spatially distributed rainfall information and its potential for regional landslide early warning systems. Nat Hazards. https://doi.org/10.1007/s11069-017-2953-9 (present issue)

Goorchi RN, Amini M, Memarian H (2017) A new rating system approach for risk analysis of rock slopes. Nat Hazards. https://doi.org/10.1007/s11069-017-3144-4 (present issue)

Guarino PM, Santo A, Forte G, De Falco M, Niceforo DMA (2017) Analysis of a database for anthropogenic sinkhole triggering and zonation in the Naples hinterland (Southern Italy). Nat Hazards. https://doi.org/ 10.1007/s11069-017-3054-5 (present issue)

Hsu C-H, Olivera F, Irish JL (2017) A hurricane surge risk assessment framework using the joint probability method and surge response functions. Nat Hazards. https://doi.org/10.1007/s11069-017-3108-8 (present issue)

Iovine G, Guagliardi I, Bruno C, Greco R, Tallarico A, Falcone G, Lucà F, Buttafuoco G (2017) Soil-gas radon anomalies in three study areas of Central-Northern Calabria (Southern Italy). Nat Hazards. https://doi.org/10.1007/s11069-017-2839-x (present issue)

Mignan A, Danciu L, Giardini D (2016) Considering large earthquake clustering in seismic risk analysis. Nat Hazards. https://doi.org/10.1007/s11069-016-2549-9 (present issue)

Persi E, Petaccia G, Sibilla S (2017) Large wood transport modelling by a coupled Eulerian-Lagrangian approach. Nat Hazards. https://doi.org/10.1007/s11069-017-2891-6 (present issue) 
Tzavella K, Fekete A, Fiedrich F (2017) Opportunities provided by geographic information systems and volunteered geographic information for a timely emergency response during flood events in Cologne, Germany. Nat Hazards. https://doi.org/10.1007/s11069-017-3102-1 (present issue)

Yin C, J-1 Zhang (2018) Hazard regionalization of debris-flow disasters along highways in China. Nat Hazards. https://doi.org/10.1007/s11069-018-3229-8 (present issue) 